\title{
Pendampingan Perancangan Pembelajaran Bahasa Inggris SMK di Masa dan Pasca-Pandemi Covid 19: Integrasi TLC Model dalam Google Classroom
}

\author{
I Made Sujana $^{1 *}$, Untung Waluyo ${ }^{1}$, Arifuddin $^{1}$, Henny Soepriyanti $^{1}$ \\ ${ }^{I}$ Pendidikan Bahasa Inggris, FKIP, Universitas Mataram, Mataram, Lombok, Indonesia
}

DOI: https://doi.org/10.29303/jpmsi.v3i1.106

Citation: Sujana, I. M., Waluyo, U., Arifuddin, A., Soepriyanti, H. 2021. Pendampingan Perancangan Pembelajaran Bahasa Inggris SMK di Masa dan Pasca-Pandemi Covid 19. Jurnal Pengabdian Masyarakat Sains Indonesia (JPMSI). 3(1):200-206.

Article history

Received: April 09 2021

Revised: June $01^{\text {th }} 2021$

Accepted: June $15^{\text {th }} 2021$

*Corresponding Author: I Made Sujana, FKIP, Universitas Mataram, Mataram, Lombok, Indonesia e-mail:

madesujana@unram.ac.id
Abstrak. Kegiatan pengabdian masyarakat ini bertujuan untuk meningkatkan kompetensi guru dalam perancangan pembelajaran di masa dan pasca pandemic COVID 19 dengan kegiatan pendampingan dan workshop pengembangan pembelajaran bauran (Blended Learning) menggunakan platform Google Classroom dipadukan dengan model pembelajaran Teaching Learning Cycles (TLC). Kegiatan dilaksanakan dalam dua tahap yaitu dengan daring (online) dengan mengembangkan bahan pelatihan melalui Google Classroom dan secara luring dengan tatap muka di sekolah. Khalayak sasaran strategis dari kegiatan ini adalah 15 orang guru Bahasa Inggris SMK yang tergabung dalam Musyawarah Guru Mata Pelajaran (MGMP) Bahasa Inggris SMK Kota Mataram dan 2 mahasiswa PS Pendidikan Bahasa Inggris FKIP UNRAM dan dipandu oleh tim pelakasana kegiatan PKM. Hasil dari kegiatan ini antara lain (1) khalayak sasaran telah mampu mengembangkan akun Google Classroom untuk mata pelajaran yang diampu dan mengembangkan Google Forms untuk kebutuhan tes online; (2) khalayak sasaran telah memiliki penegtahuan tentang teknik pembuatan video dengan menggunakan slideshow dan screen cast o matic, pengembangan game-game pembelajaran Bahasa Inggris, perancangan Bahasa Inggris dengan model Teaching Learning Cycles (TLC), dan cara mengintegrasikan Google Meet dan Google Forms ke dalam Google Classroom.

Kata kunci: Blended Learning, TLC, Google Classroom, Bahasa Inggris, SMK

Abstract. This community service activity aims to improve teacher competence in designing learning during and after the COVID 19 pandemic with mentoring activities and workshops for developing blended learning using the Google Classroom platform combined with the Teaching Learning Cycles (TLC) model. The activity is carried out in two stages, namely online by developing training materials through Google Classroom and offline face-to-face at school. The strategic target audience of this activity were 15 English teachers from vocational schools as members of an MGMP organization and 2 students of the English Education Study Program, FKIP Unram and were managed by the community service team. The results of this activity include (1) the target audience has managed to develop a Google Classroom account for the subjects being taught and Google Forms for online test needs; (2) the target audience has already knowledge and practice on video creation using slideshows and screen cast-o-matic, developing English learning games, and the use of Teaching Learning Cycles (TLC) model. They are also capable of integrating Google Meet and Google Forms into in Google Classroom.

Keywords: Blended Learning, TLC, Google Classroom, English, SMK 
Sujana et al, Jurnal Pengabdian Masyarakat Sains Indonesia 2021, 3 (1) 200-206. DOI : https://doi.org/10.29303/jpmsi.v3i1.106

\section{Pendahuluan}

Kegiatan Pengabdian pada Masyarakat ini dilatarbelakangi oleh beberapa perubahan orientasi pembelajaran Bahasa Inggris dalam Kurikulum 2013 (Kemdikbud, 2017) dan tuntutan pembekalan keterampilan abad 21 untuk mempersiapan gernerasi muda dalam menghadapi Era Revolusi Industri 4,0 (Fadel, 2012; NCREL, 2003), serta tuntutan pembelajaran di masa dan pasca pandemic Covid 19 yang mengisyaratkan penerapan Blended/Hybrid Learning (Indrajit, 2020).

Dengan pemberlakuan K-13, pembelajaran Bahasa Inggris mengalami perubahan antara lain (a) pengurangan jam belajar dari 4-5 jam per minggu menjadi 2-3 jam per minggu dan (b) untuk jenjang SMK adanya penyamaan antara materi bahasa Inggris SMA dengan Bahasa Inggris SMK (Kemdikbud, 2017). Dua kebijakan ini dianggap sebagai sebuah kemunduran dalam kebijakan kurikulum, dimana di saat Indonesia menyongsong dan berada pada Pembelajaran Abad 21 dan Era Revolusi Industri 4.0, pembekalan terhadap penguasaan Bahasa Inggris dikurangi, bahkan di Sekolah Dasar dihapuskan. Penyamaan antara kurikulum dan materi SMK dengan SMA juga merupakan suatu kemunduran.

Bahasa Inggris SMK telah lama menerapkan pendekatan English for Specific Purposes/ESP (Pendekatan Pembelajaran Bahasa Inggris untuk Tujuan Khusus), yaitu pendekatan perancangan pembelajaran Bahasa Inggris berdasarkan pada kebutuhan pembelajar (Basturkman, 2010; Brown, 2016). Pembelajaran di SMK diarahkan pada dunia kerja, sehingga pembelajaran Bahasa Inggris juga dirancang sesuai dengan bidang mereka. Pada kurikulum sebelumnya, arah pembelajaran Bahasa Inggris disesuaikan dengan bidang masing-masing. Widodo (2016) menegaskan bahwa pembelajaran Bahasa Inggris di sekolah kejuruan diarahkan pada penguasaan komunikasi (lisan/tulis) sesuai dengan bidangnya masing-masing. Pemenuhan kebutuhan dan minat peserta didik dalam belajar Bahasa Inggris akan meningkatkan efektivitas dan efisiensi dalam belajar (Sujana, Fitriana, \& Syahrial, 2016; Sujana, 2003).

Permasalahan lain yang dihadapi oleh pembelajaran Bahasa Inggris di SMK adalah adanya tuntutan untuk menyiapkan sumber daya manusia (SDM) yang memiliki Keterampilan Pembelajaran Abad 21 untuk menyambut Era
e-ISSN : 2715-2537

p-ISSN : 2715-2545

Revolusi Industri 4,0. Menghadapi tantangan Revolusi Industri 4.0 yang ditandai dengan digitalisasi dan otomatisasi dalam berbagai aspek kehidupan, guru dituntut untuk lebih kreatif dan inovatif dalam merencanakan, melaksanakan, dan menilai pembelajaran. Pemerintah Indonesia melalui Kemendikbud dan Kemenristekdikti telah mengupayakan pembaharuan penyelenggaraan pendidikan dasar sampai perguruan tinggi, diantaranya dengan (1) mengembangkan Keterampilan Pembelajaran Abad $21\left(21^{\text {st }}\right.$ Century Learning Skills) dan (2) menerapakan Pembelajaran Bauran (Blended/Hybrid Learning) (Belmawa, 2018; lihat juga NCREL, 2003; Fadel, 2012). Untuk dapat mencapai tuntutan tersebut diperlukan model-model pembelajaran yang inovatif dan berpusat pada peserta didik.

Masalah lain yang melanda pendidikan secara global adalah merebaknya wabah Corona 19 sejak awal Maret 2020. Wabah ini memaksa guru untuk mengajar dari rumah secara online. Perubahan tibatiba dari pembelajaran total tatap muka menjadi pembelajaran total online membuat kepanikan pada semua pihak (guru, peserta didik, pemegang kebijakan). Sebagian besar guru belum siap untuk menerapkan pembelajaran secara online, tanpa pilihan. Ketidaksiapan ini menimbulkan berbagai reaksi dari guru. Kalau situasi seperti ini dibiarkan tanpa solusi, yang menjadi korban adalah peserta didik sebagai generasi penerus. Mereka bisa dipastikan tidak memiliki bekal pengetahuan dan keterampilan untuk bersaing secara global.

Menghadapi berbagai kendala dalam pendidikan di SMK, kegiatan Pengabdian kepada Masyarakat ini diarahkan pada pemberian pembinaan pembelajaran Bahasa Inggris dengan pendampingan guru-guru Bahasa Inggris SMK secara bertahap dengan menggunakan pola MGMP binaan. Guru akan dibina untuk mengembangkan Blended Learning dan penerapan model pembelajaran Teaching Learning Cycles (TLC). TLC Model adalah suatu model pembelajaran yang terdiri dari 4 tahapan pembelajaran yang saling berkaitan, yaitu Building Knowledge of the Field (BKOF), Modelling of the Text (MOT), Joint Construction of the Text (JCOT), dan Independent Construction of the Text (ICOT) (Callaghan \& Rothery, 1988). Langkah-langkah terintegrasi dari model ini mampu memberikan MODAL dan sekaligus MODEL yang digunakan dalam kegiatan 
Sujana et al, Jurnal Pengabdian Masyarakat Sains Indonesia 2021, 3 (1) 200-206. DOI : https://doi.org/10.29303/jpmsi.v3i1.106

PRACTICE dan PRODUCTION (Sujana, Waluyo, Soepriyanti, \& Arifuddin, 2019).

Solusi pembelajaran online adalah dengan menggunakan platform Google Classroom (GC). GC adalah sebuah serambi (platform) pembelajaran online yang diranjang untuk memudahkan mahasiswa dan dosen untuk berkomunikasi, berkolaborasi, mengorganisir dan mengelola materi, tugas, angket, dan kegiatan lainnya (Keeler \& Miller, 2015; Bell, 2015). Dipilihnya GC sebagai Learning Management System dalam kegiatan ini mengingat kelebihan GC antara lain: mudah dioperasikan, proses setting cepat dan nyaman, berbagi sumber dengan cepat, menyimpan data terpusat, meningkatkan kerjasama komunitas. Tahapan-tahapan yang dilakukan dalam kegiatan PKM ini adalah (1) penanaman konsep TLC Model dan Google Classroom; (2) Pengembangan Materi F2F dengan TLC dan online dengan Google Classroom (GC); (3) Pelaksanaan Blended Learning. Pendampingan dilakukan dengan pola multi-years sampai khalayak sasaran mampu menerapkan dan mengevaluasi pembelajarannya.

Kegiatan Pengabdian kepada Masyarakat ini bertujuan untuk: (1) meningkatkan kompetensi guru-guru Bahasa Inggris SMK Kota Mataram dalam mengelola pembelajaran Blended berbasis Google Classroom dengan Teaching Learning Cycle (TLC) Model; (2) mengembangkan materi Bahasa Inggris SMK dengan menggunakan Model TLC; (3) mengembangkan berbagai materi dan instrument dngan Google Form untuk menunjang Blended Learning berbasis Google Classroom.

\section{Metode}

Khalayak sasaran strategis dari kegiatan Pengabdian pada Masyarakat ini adalah 15 guru Bahasa Inggris SMK Kota Mataram Lombok NTB dan 2 mahasiswa PS Pendidikan Bahasa Inggris dengan melibatkan Tim Pengabdian pada Masyarakat PS Pendidikan Bahasa Inggris FKIP UNRAM. Rangkaian kegiatan secara keseluruhan dilaksanakan selama 8 bulan, dengan langkahlangkah pelaksanaan kegiatan meliputi tahapan persiapan, tahapan pelaksanaan kegiatan, dan tahap evaluasi kegiatan.

\section{Tahap Persiapan}

Pada tahap persiapan, tim secara kolaboratif mengembangkan materi yang digunakan pada kegiatan online dengan menggunakan platform
e-ISSN : 2715-2537

p-ISSN : 2715-2545

Google Classroom dan mengembangan materi yang akan digunakan pada kegiatan offline (workshop). Pada tahapan ini, tim juga mengembangkan kuesioner untuk menggali permasalahan yang dihadapi dalam pembelajaran online.

2. Tahap Pelaksanaan

Tahap pelaksanakan dilakukan dengan pendampingan dan workshop. Pendampingan dilakukan dengan moda daring (online) dengan menggunakan materi yang dikembangkan dalam Google Classroom dan melalui WhatsApp, sedangkan workshop dilakukan secara luring (offline). Secara dari dilakukan dengan memberikan materi-materi pelatihan dalam rumah Google Classroom untuk dipelajari secara mandiri oleh khalayak sasaran. Kegiatan luring dilaksnakan di SMKN 3 Mataram.

3. Tahap Evaluasi

Tahap evaluasi kegiatan dilakukan dengan pengamatan produk, proses kegiatan, dan refleksi kegiatan oleh perwakilan guru.

\section{Hasil dan Pembahasan}

Hasil yang diperoleh dari rangkaian kegiatan pengabdian pada masyarakat ini antara lain tersusunnya akun Google Classroom yang berisi materi pendampingan dan workshop untuk pengembangan pembelajaran online. Materi yang dikembangkan pada GC terdiri dari 6 unit atau bagian, yaitu: (1) Pembelajaran di masa Covid, berisi tentang konsep-konsep pembelajaran di masa Covid 19 untuk memberikan wawasan pada guruguru tentang peran yang harus dilakukan di masa pandemic ini; (2) Pengembangan Google Classroom, yang berisi handout/panduan langkah langkah pengembangan GC dan video-video tentang pembuatan GC; (3) Pengembangan Google Forms, memuat panduan pembuatan soal, LKPD dengan menggunakan GF yang disajikan dalam format panduan dan video-video. Pada unit ini juga diperkenalkan cara-cara mentransfer soal dari words/pdf menjadi GF dalam waktu singkat; (4) Pengembangan Video pembelajaran, berisi tentang bagaimana membuat video pemeblajaran dengan slideshow dan screen-cast-o-matic; Mengintegrasikan GC dengan Google Meet dan GF; (6) Sample pengambangan materi dengan model TLC. Berikut adalah sampel tampilan GC. 


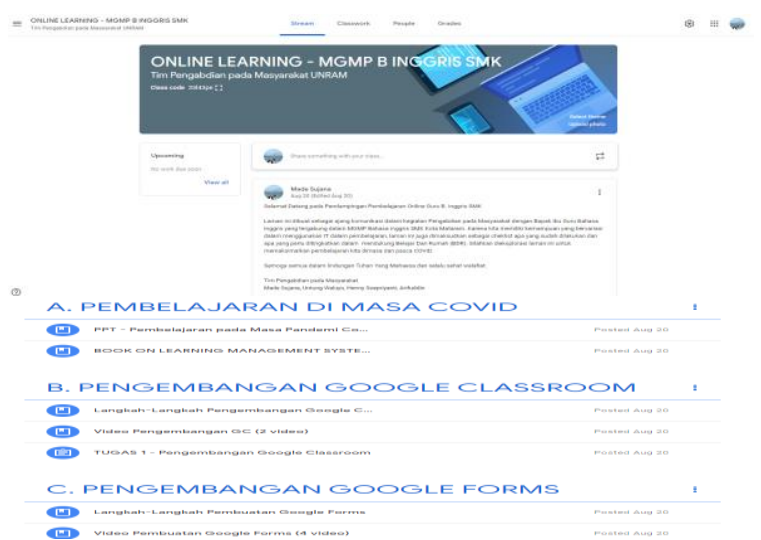

Gambar 1. Tampilan Google Classroom

Kegiatan pendampingan dilakukan dengan memberikan akun Google Classroom kepada khalayak sasaran. Mereka diminta untuk mempelajari secara bertahap materi-materi dan mempraktekannya untuk menghemat waktu kegiatan workshop tatap muka. Komunikasi dilakukan dengan Forum di GC dan WhatsApp. Setelah peluncuran akun GC selama 2 bulan (September - Oktober), khalayak sasaran diberikan kuesioner untuk menggali permasalahan guru dalam pembelajaran online Hasil ini menjadi dasar untuk mendampingi guru dalam kegiatan workshop (tatap muka). Beberapa informasi diperoleh dari survei tersebut antara lain:

1. Semua khalayak sasaran telah mengembangkan Google Classroom untuk kelas merekan masingmasing, serta telah dicobakan, walalupun pelaksanaannya belum maksimal karena berbagai kendala di lapangan.

2. Sebagian guru telah mencoba membuat soal dengan Google Forms, namun masih mengalami kendala dalam pemberian bobot, kunci jawaban.

3. Rata-rata guru belum mengembangkan video pembelajarannya sendiri.

4. Kebanyakan guru belum pernah mengintegrasi antara GC dengan Google Meet.

5. Guru belum memanfaatkan software untuk membuat permainan untuk menarik perhatian peserta didik.

Dari hasil survei penggunaan bahan pelatihan berbasis GC, kegiatan luring dilaksanakan dengan mengakomodasi masukan khalayak sasaran. Kegiatan luring dilaksanakan pada hari Rabu 11 November 2020 bertempat di SMKN 3 Mataram. Mengikuti protocol Covid 19, peserta dibatasi hanya 15 orang dari untur guru dan mahasiswa. Kegiatan dipandu oleh fasilitator dari PS
e-ISSN : 2715-2537

p-ISSN : 2715-2545

Pendidikan Bahasa Inggris. Adapun materi yang disajikan antara lain: Pembelajaran di Masa dan Pasca Covid 19 disajikan oleh Drs. H. Untung Waluyo, MA., Ph.D. Dra. Hj. Henny Soepriyanti, MA., Ph.D.; Review Pengembangan CG, GF, dan Cara transfer Word document menjadi GF disajikan oleh Drs. I Made Sujana, M.A \& Prof. Arifuddin; Pengembangan video pembelajaran dan game oleh Drs. I Made Sujana, M.A \& Prof. Arifuddin; dan TLC Model dalam GC disajikan Drs. I Made Sujana, M.A dan Integrasi GM dalam GC oleh Drs. I Made Sujana, MA.

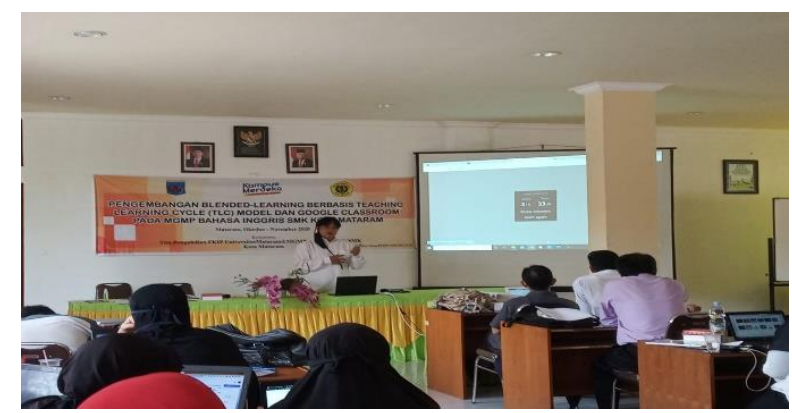

Gambar 2. Pengembangan game berbasis Wordwall

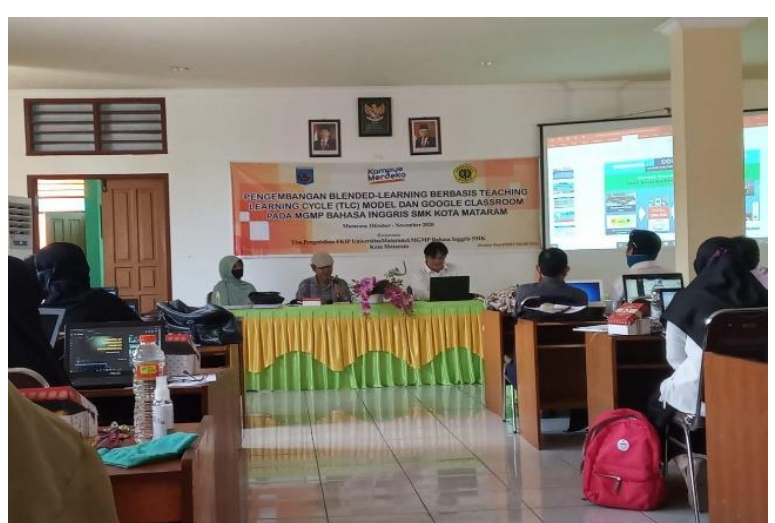

Gambar 3. Pemaparan Pembelajaran di masa Covid 19

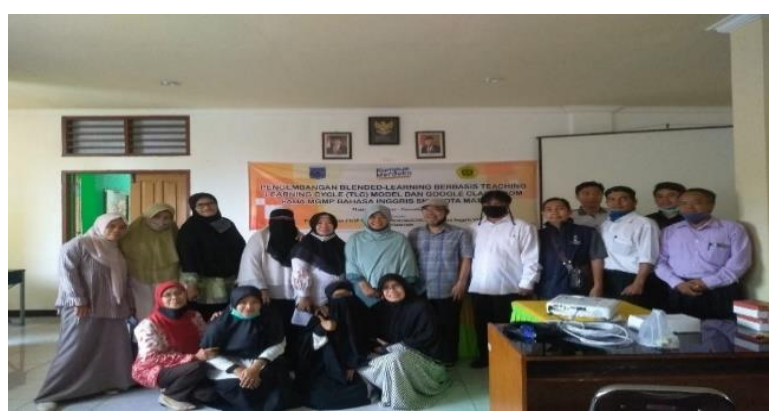

Gambar 4. Peserta dan Narasumber

Dari rangkaian kegiatan daring dan luring, kegiatan pengabdian ini telah mencapai tujuan yang dicanangkan dalam kegiatan PKM ini. Dengan 
Sujana et al, Jurnal Pengabdian Masyarakat Sains Indonesia 2021, 3 (1) 200-206. DOI : https://doi.org/10.29303/jpmsi.v3i1.106

pengembangan GC mengawali tatap muka, kegiatan pengabdian ini bisa menghemat waktu kegiatan workshop karena peserta telah mempelajari materi dan bahkan telah mengembangkan secara mandiri Google Classroom untuk mata kuliah mereka masing-masing.
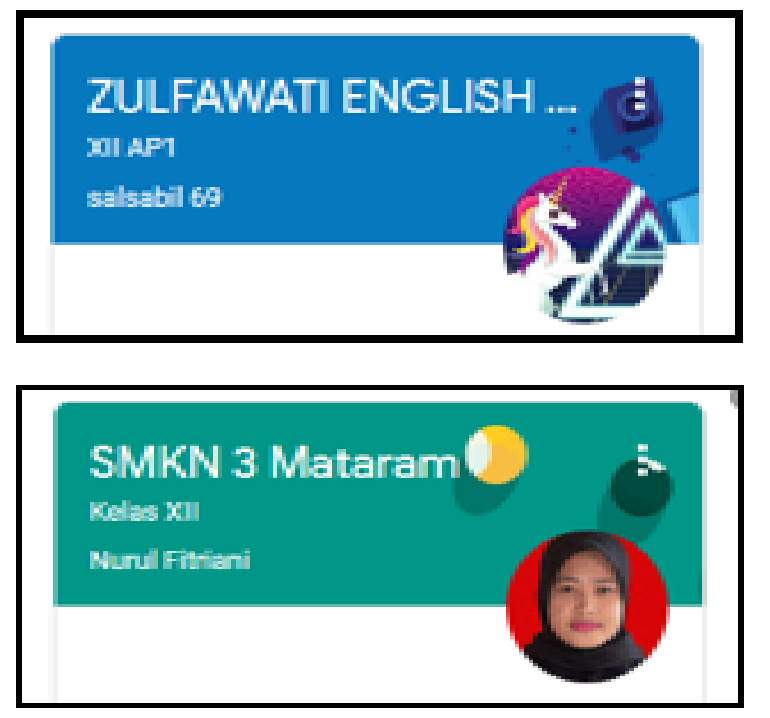

Gambar 5. Sampel GC guru B Inggris SMK

Kegiatan luring, berdasarkan masukan dari survei, diarahkan pada pengembangan google forms, cara pengembangan video dari powerpoint dan screencast-o-matic, dan, integrasi antara GC dengan GM, dan pengembangan materi berbasis TLC.

Secara keseluruhan kegiatan pengabdian pada masyarakat ini telah mencapai tujuan yang dicanangkan, yaitu: (1) membekali khalayak sasaran dengan berbagai kebutuhan pembelajaran online yang dapat digunakan pada pembelajaran di masa maupun pasca Covid 19; (2) khalayak sasaran telah mampu mengembangkan Google Classroom mata pelajarannya masing-masing dengan panduan GC yang diberikan; (3) khalayak sasaran telah mampu mengembangkan google forms untuk keperluan tes; (4) khalayak sasaran juga telah memiliki pengetahuan tentang pengemabangan pembelajaran dengan TLC model, mengintegrasikan GC, GF, dan GM dalam pembelajaran masing-masing.

Sehubungan dengan keterbatasan waktu yang tersedia dan padatnya materi yang disampaikan, kegiatan PKM ini perlu dilanjutkan dengan kegiatan-kegiatan serupa di masa
e-ISSN : 2715-2537

p-ISSN : 2715-2545

mendatang untuk mengawal keberlanjutan dari kegiatan ini, sesuai dengan program yang dicanangakan pemerintah melalui program pengembangan keprofesian berkelanjutan (PKB) (Ditjen. GTK, 2019).

Dari sambutan yang disampaikan ketua MGMP B Inggris SMK Kota Mataram tergambar bahwa kegiatan ini telah memberikan manfaat pada pengembangan kompetensi guru di masa Covid 19 dan berharap kerjasama serupa bisa diteruskan untuk mengaktifkan program kerja MGMP B Inggris SMK Kota Mataram. Dari hasil wawancara dengan beberapa peserta, disimpulkan bahwa perlu ada tindak lanjut kegiatan ini untuk memaksimalkan penggunaan online learning dalam format Blended Learning dan adanya bimbingan untuk menghasilkan karya ilmiah dari kegiatan pembelajaran mereka masing-masing.

\section{Kesimpulan}

Berdasarkan kegiatan yang dilaksanakan secara daring dan luring, dapat disimpulkan bahwa kegiatan pengabdian pada masyarakat ini telah terlaksana sesuai dengan perencanaan kegiatan yaitu dengan melibatkan 15 guru Bahasa Inggris SMK dan 2 orang mahasiswa dan telah dilaksanakan sesuai dengan protocol Covid 19. Khalayak sasaran telah mampu mengembangkan akun Google Classroom untuk mata pelajaran yang diampu dan mengembangkan Google Forms untuk kebutuhan tes online. Khalayak sasaran telah memiliki penegtahuan tentang teknik pembuatan video dengan menggunakan slideshow dan screen cast o matic, pengembangan game-game pembelajaran Bahasa Inggris (wordwall), perancangan Bahasa Inggris dengan model Teaching Learning Cycles (TLC), dan cara mengintegrasikan Google Meet dan Google Forms ke dalam Google Classroom.

\section{Saran}

Saran untuk para guru dan mahasiswa (khalayak sasaran) antara lain 1). Pembelajaran Bauran (Blended Learning) akan menjadi satu bentuk pembelajaran pasca Covid. Guru dan peserta didik sudah terbiasa dengan pembelajaran online sehingga akan memudahkan pelaksanaan pembelajaran BL 2). Diperlukan proses yang 
Sujana et al, Jurnal Pengabdian Masyarakat Sains Indonesia 2021, 3 (1) 200-206. DOI : https://doi.org/10.29303/jpmsi.v3i1.106

panjang untuk dapat menggunakan GC secara sempurna dalam BL. Guru disarankan untuk terus berurasaha untuk mengisi konten sesuai dengan kelas yang diajarkan. Setelah memiliki "rumah" dan kontennya, khalayak sasaran perlu mengimplimentasikan dalam pembelajaran untuk menunjang pembelajaran tatap muka. 3). Dalam implementasinya, guru bisa memanfaatkan hasil penerapannya menjadi karya tulis penelitian dan/atau artikel publikasi untuk meningkatkan produltivitas guru, dan 4). Diperlukan saling berbagi materi untuk guru yang mengajar di kelas yang sama (resource sharing) untuk memperkaya konten GC masing-masing.

\section{Ucapan Terima Kasih}

Penulis mengucapkan terima kasih kepada:

1. Tim Pengabdian kepada Masyarakat PS Pendidikan Bahasa Inggris UNRAM mengucapkan terima kasih kepada Universitas sebagai penyandang dana kegiatan PKM ini melalui Dana DIPA BLU tahun anggaran 2020.

2. MGMP Bahasa Inggris SMK Kota mataram Lombok atas bantuannya untuk mengkoordinir kegiatan dan menyediakan fasilitas kegiatan workshop

\section{Daftar Pustaka}

Basturkmen, H. (2010) Developing Courses in English for Specific Purposes. McMillan: Palgrave.

Bell, K. (2015) The Teacher's Guide to Google Classroom. Texas: Shake Up Learnig, LLC

Belmawa (2018) Panduan Penyusunan Kurikulum Perguruan Tinggi dalam Era Revolusi Industri 4.0. Jakarta: Belmawa Kemenristekdikti.

Brown, J. D. (2016). Introducing Needs Analysis and English for Specific Purposes. Oxford: Routledge.

Callaghan, M. dan J. Rothery, 1988. Teaching Factual Writing: A Genre-Based Approach. Report of DSP Literacy Project Metropolitan East Region Sydney NSW School, Education Department.

Ditjen GTK (2019) Program Pengembangan Keprofesian Berkelanjutan (PKB) melalui Peningkatan Kompetensi Pembelajaran
e-ISSN : 2715-2537

p-ISSN : 2715-2545

(PKP) berbasis Zonasi: Pedoman. Jakarta: Ditjen GTK, Depdikbus,

Fadel, C. (2012). What should students learn in the 21st century? accessed from https://k12.thoughtfullearning.com/FAQ/ what-are-21st-century-skills on 24 January 2019

Indrajit, R.E. (2020). Protret Perkuliahan Daring di Masa Covid 19 dalam perspektif literasi digital: Suatu refleksi pengelaman. Dalam $\mathrm{T}$ Belawati \& Nizam (eds.) Potret Pendidikan Tinggi di Masa Covid 19. (pp, 45-76). Jakarta: Ditjen Dikti Kemdikbud.

Kemdikbud (2017). Model Silabus Mata Pelajaran SMA/MA/SMK: Mata Pelajaran Bahasa Inggris. Jakarta: Kemdikbud

Keeler, A. dan Miller, L. (2015) 50 Things You Can Do with Google Classroom. San Diego, CA: Dave Burgess Consulting, Ltd.

NCREL. (2003) enGauce 2 $1^{\text {st }}$ Century Skills: Lietracy in Digitas Age. Illinois: NCREL $\&$ Metiri Group. accessed on 23 January 2019 from file:///Revolusi\%20Industri\%204.0\%20da n\%2021\%20Century\%20Learning/engaug e21st.pdf

Singh, H. and Reed, C. (2001) A White Paper: Achieving Success with Blended Learning. Available online at www.p2paertner.co.uk

Sujana, I M. (2003) Establishing English Competencies for Students of Tourism Department University of Mataram: A Proposal. A paper presented at NUESP National Conference, Universitas Jember, 4-5 Agustus 2003.

Sujana, I. M., Fitriana, E., \& Syahrial, E. (2016). Conflicts among Aspects of Needs in Designing the Teaching of English using an ESP Approach at Higher Education in Indonesia. In M. M. Rahman, Integrating Technology and Culture: Strategies and Innovation in ELT (pp. 171-205). Jaipur , India: YKing Books.

Sujana, I M., Waluyo, U., Soepriyanti, H., \& Arifuddin (2019). Penerapan Deconstruction-Construction Model dalam Menyusun Penelitian Tindakan Kelas (PTK) untuk Guru-Guru Bahasa Inggris Kota Mataram. Jurnal Pendidikan 
Sujana et al, Jurnal Pengabdian Masyarakat Sains Indonesia 2021, 3 (1) 200-206. DOI : https://doi.org/10.29303/jpmsi.v3i1.106

dan Pengabdian Masyarakat, 2(2), 189196

Widodo, H. P. (2016). Teaching English for Specific Purposes (ESP): English for Vocational Purposes (EVP). In W. A. Renandya \& H. P. Widodo (Eds.), English Language Teaching Today: Linking Theory and Practice (pp. 277-291). Springer International Publishing. https://doi.org/10.1007/978-3-319-38834219 